Thorax (1968), 23, 1.

\title{
Mitral valve replacement \\ Long-term results, with particular reference to changes in pulmonary vascular resistance
}

\author{
J. HAMER, T. BOULTON, J. FLEMING, G. W. HAYWARD, \\ I. M. HILL, I. MONRO, G. SIMON, AND C. S. TUBBS
}

From St. Bartholomew's Hospital, London, E.C.1

\begin{abstract}
The first 16 patients to have mitral valve replacement with the Starr-Edwards prosthesis at St. Bartholomew's Hospital, London, were reviewed from one to three years after operation. These patients had presented with serious mitral valve disease and there was a high incidence of severe dyspnoea and persistent congestive failure before operation. There were four operative deaths, and two survivors had poor results due to regurgitation alongside the prosthesis. The remaining 10 patients showed considerable improvement. Although no diuretics were given after operation there was little dyspnoea and congestive failure resolved. Anticoagulant therapy is given after operation, and there have been few embolic incidents. The pulmonary vascular resistance was raised to between 6 and 11 units before operation in six patients. There was no undue mortality in this group, and post-operative cardiac catheterization showed a considerable fall in resistance and an increase in cardiac output, suggesting resolution of the pulmonary vascular obstruction. Tricuspid incompetence in these patients disappeared post-operatively. We conclude that mitral valve replacement can restore a patient severely disabled by mitral valve disease to a nearly normal life. We do not regard pulmonary hypertension as a contraindication to operation.
\end{abstract}

Starr and Edwards (1961) showed that it was possible to correct the mechanical abnormalities in mitral valve disease by replacing the valve with a mechanical prosthesis, and they demonstrated that the procedure gave effective relief of symptoms in patients with serious disability. Replacement of the mitral valve with the Starr-Edwards prosthesis has been performed in 50 patients at St. Bartholomew's Hospital since the end of 1963, and there are 39 survivors, a mortality rate of $22 \%$. Our first successful mitral valve replacement was performed as a desperate measure in a severely ill patient with considerable pulmonary vascular obstruction (Fig. 1). Following this experience we have continued to operate on such patients, and we do not regard the presence of pulmonary vascular disease as a contraindication to mitral valve replacement. As a result of this policy many of our patients have had serious congestive heart failure with tricuspid incompetence at the time of operation. There has been a gratifying improvement in the pulmonary vascular obstruction and in the congestive failure after operation in these patients.
The present report is based on the post-operative evaluation of the 16 patients operated on before October 1965. Four of these patients died at operation. The 12 survivors have been followed for from one to three years, with particular reference to the fall in pulmonary vascular resistance which has followed the operation.

\section{METHODS}

Clinical features before and after operation have been classified as slight, moderate, severe or gross abnormalities and coded from 0 (for normal) to 4 on this basis. Congestive failure was regarded as slight if the venous pressure was controlled by diuretic therapy, and as gross if hepatic pulsation or severe oedema persisted in spite of this treatment. Right and left ventricular hypertrophy were assessed separately from clinical examination with the help of the electrocardiogram. The radiographs were assessed by two observers (G.S. and J.H.) without reference to the clinical findings. The heart size in the postero-anterior view was expressed as the cardiothoracic ratio-that is, the ratio of the maximum transverse diameter of the heart to the internal diameter of the thoracic cage at the level of the dome of the diaphragm. 

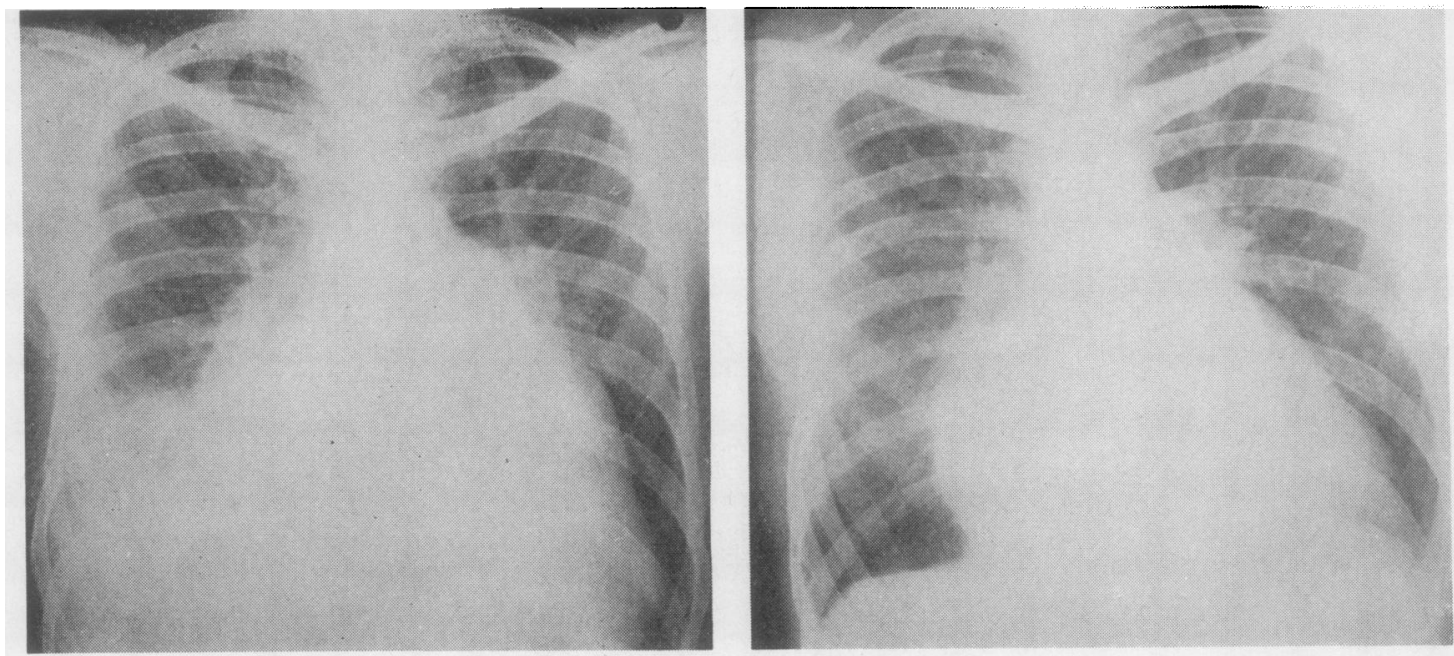

FIG. 1. L.S. Pre-operative (left) and post-operative (right) chest radiographs. This patient, with a pulmonary vascular resistance of 10 units, was operated on as a desperate measure in intractable congestive heart failure.

Cardiac catheterization was performed after premedication with promethazine, $50 \mathrm{mg}$. intramuscularly. A Cournand catheter was passed from a basilic vein to the pulmonary artery. Pressures were measured with a Statham P23G strain gauge with a baseline at the sternal angle and were recorded photographically. Cardiac output was measured on the Fick principle, using the Haldane method to analyse expired air and the Van Slyke method for blood oxygen content. Predicted values for oxygen consumption were used in 10 instances.

Three different methods of open heart surgery were used in these patients. In four early cases (G. W., V.G., E. C., and C. H.) the operation was performed under profound hypothermia at a minimum oesophageal temperature of $7^{\circ}$ to $9^{\circ} \mathrm{C}$. In three patients (I. S., L. S., and G. R.) cardiopulmonary bypass with a Melrose or Kay-Cross disc oxygenator was used, with moderate hypothermia $\left(11^{\circ}\right.$ to $22^{\circ} \mathrm{C}$.). The remaining nine patients were operated on at $26^{\circ}$ to $30^{\circ} \mathrm{C}$., using the Baxter bag. Tracheostomy was performed in all these patients, and artificial ventilation with a Radcliffe respirator was maintained for a period varying from several days to three weeks after operation. There was no serious infection of the tracheostomy.

\section{RESULTS}

PRE-OPERATIVE ASSESSMENT The clinical findings before operation are shown in Table I. The $\underline{3}$.

T A B L E I

CLINICAL EVALUATION BEFORE AND AFTER OPERATION

\begin{tabular}{|c|c|c|c|c|c|c|c|c|c|c|c|c|c|}
\hline \multirow[b]{2}{*}{ Patient } & \multirow[b]{2}{*}{ Sex } & \multirow[b]{2}{*}{ Age } & \multicolumn{4}{|c|}{ Pre-operative Condition } & \multirow{2}{*}{$\begin{array}{c}\text { Mitral } \\
\text { Valve } \\
\text { Lesion }\end{array}$} & \multirow{2}{*}{$\underset{\operatorname{up}_{\text {(mths) }}}{\text { Follow- }}$} & \multicolumn{4}{|c|}{ Post-operative Condition } & \multirow{2}{*}{$\begin{array}{l}\text { Mitral } \\
\text { Valve } \\
\text { Lesion }\end{array}$} \\
\hline & & & $\begin{array}{c}\text { Dyspnoea } \\
(0 \text { to } 4)\end{array}$ & $\begin{array}{l}\text { Failure } \\
(0 \text { to } 4)\end{array}$ & $\begin{array}{l}\text { L.V.H. } \\
(0 \text { to } 4)\end{array}$ & $\begin{array}{l}\text { R.V.H. } \\
\text { (0 to 4) } \\
\end{array}$ & & & $\begin{array}{c}\text { Dyspnoea } \\
(0 \text { to } 4)\end{array}$ & $\begin{array}{l}\text { Failure } \\
(0 \text { to } 4)\end{array}$ & $\begin{array}{l}\text { L.V.H. } \\
\text { (0 to 4) }\end{array}$ & $\begin{array}{l}\text { R.V.H. } \\
(0 \text { to } 4)\end{array}$ & \\
\hline $\begin{array}{l}\text { I. S. } \\
\text { L.S. } \\
\text { G. W. } \\
\text { A. C. } \\
\text { V. G. } \\
\text { E. C. } \\
\text { C. H. } \\
\text { J. O. } \\
\text { J. M. } \\
\text { D. B. } \\
\text { H. B. } \\
\text { D. E. } \\
\text { A. L. } \\
\text { E. A. } \\
\text { E. G. } \\
\text { G. R. }\end{array}$ & $\begin{array}{c}\mathbf{F} \\
\mathbf{M} \\
\mathbf{F} \\
\mathbf{F} \\
\mathbf{F} \\
\mathbf{F} \\
\mathbf{F} \\
\mathbf{M} \\
\mathbf{M} \\
\mathbf{F} \\
\mathbf{M} \\
\mathbf{F} \\
\mathbf{F} \\
\mathbf{F} \\
\mathbf{M}\end{array}$ & $\begin{array}{l}49 \\
41 \\
52 \\
31 \\
53 \\
38 \\
29 \\
37 \\
52 \\
55 \\
47 \\
45 \\
46 \\
56 \\
34 \\
34\end{array}$ & $\begin{array}{l}4 \\
3 \\
3 \\
4 \\
4 \\
4 \\
3 \\
4 \\
3 \\
3 \\
3 \\
4 \\
3 \\
3 \\
4 \\
3\end{array}$ & $\begin{array}{l}4 \\
3 \\
1 \\
1 \\
1 \\
1 \\
3 \\
1 \\
2 \\
2 \\
1 \\
1 \\
1 \\
3 \\
3 \\
3 \\
3 \\
2\end{array}$ & $\begin{array}{l}2 \\
2 \\
3 \\
0 \\
2 \\
2 \\
3 \\
1 \\
2 \\
1 \\
2 \\
3 \\
3 \\
3 \\
2 \\
1\end{array}$ & $\begin{array}{l}2 \\
1 \\
1 \\
2 \\
0 \\
2 \\
1 \\
3 \\
1 \\
2 \\
2 \\
2 \\
3 \\
3 \\
3 \\
4\end{array}$ & $\begin{array}{l}\text { M.I. (M.S.) } \\
\text { M.I. (M.S.) } \\
\text { M.I. } \\
\text { M.I. } \\
\text { M.I. (M.S.) } \\
\text { M.I. (M.S.) } \\
\text { M.I.(M.S.) } \\
\text { CaM.S. (M.I.) } \\
\text { CaM.S. (M.I.) } \\
\text { CaM.S.(M.I.) } \\
\text { M.I. (M.S.) } \\
\text { M.I. (M.S.) } \\
\text { M.I. (M.S.) } \\
\text { M.I.(M.S.) } \\
\text { CaM.S. (M.I.) } \\
\text { CaM.S. (M.I.) }\end{array}$ & $\begin{array}{r}2 \\
29 \\
28 \\
28 \\
2 \\
26 \\
2 \\
21 \\
20 \\
20 \\
19 \\
19 \\
18 \\
2 \\
16 \\
13\end{array}$ & $\begin{array}{l}1 \\
1 \\
1 \\
1 \\
0 \\
3 \\
1 \\
3 \\
2 \\
1 \\
1 \\
1\end{array}$ & $\begin{array}{l}0 \\
0 \\
0 \\
0 \\
0 \\
1 \\
0 \\
1 \\
0 \\
0 \\
0 \\
0\end{array}$ & $\begin{array}{l}2 \\
1 \\
0 \\
1 \\
1 \\
1 \\
1 \\
2 \\
0 \\
2 \\
2 \\
1\end{array}$ & $\begin{array}{l}0 \\
0 \\
0 \\
0 \\
\\
1 \\
0 \\
0 \\
1 \\
1 \\
1 \\
1 \\
1 \\
2\end{array}$ & $\begin{array}{l}\overline{-} \\
- \\
\overline{\text { M.I. }} \\
\overline{\text { M.I. }} \\
\overline{-} \\
\overline{-}\end{array}$ \\
\hline
\end{tabular}

${ }^{1}$ Normal sinus rhỵthm. ${ }^{2}$ Fatal cases. M.I., mitral incompetence; M.S., mitral stenosis; CaM.S., calcific mitral stenosis. 
patients were six men and 10 women between 29 and 56 years of age. These patients all needed diuretic therapy before operation, and the clinical state after optimal treatment is recorded. Serious breathlessness was a constant feature. Severe congestive failure was associated with serious tricuspid incompetence and was present in seven of the patients before operation. All the patients had severe mitral valve disease, and all but one had atrial fibrillation. Previous valvotomies had been performed in seven patients, with good results in four but with the production of mitral incompetence in the other three. In A. C., a blind patient operated on for moderate mitral stenosis during pregnancy, serious mitral incompetence required valve replacement a few hours after the valvotomy. Four patients had had systemic emboli in the past.

Clinical assessment indicated at least moderate left ventricular hypertrophy in 12 patients, and 11 had a similar degree of right ventricular hypertrophy. The cardiothoracic ratio on radiography was over $60 \%$ in 12 patients, and there was often considerable enlargement of the right atrium, left atrium, and pulmonary artery, but the last finding was not confined to patients with pulmonary vascular obstruction. It was difficult to assess the changes in the pulmonary arteries in the lower zones, as these were often obscured by the large heart. There was evidence of pulmonary congestion at the time of operation in nearly all the patients (Fig. 2).

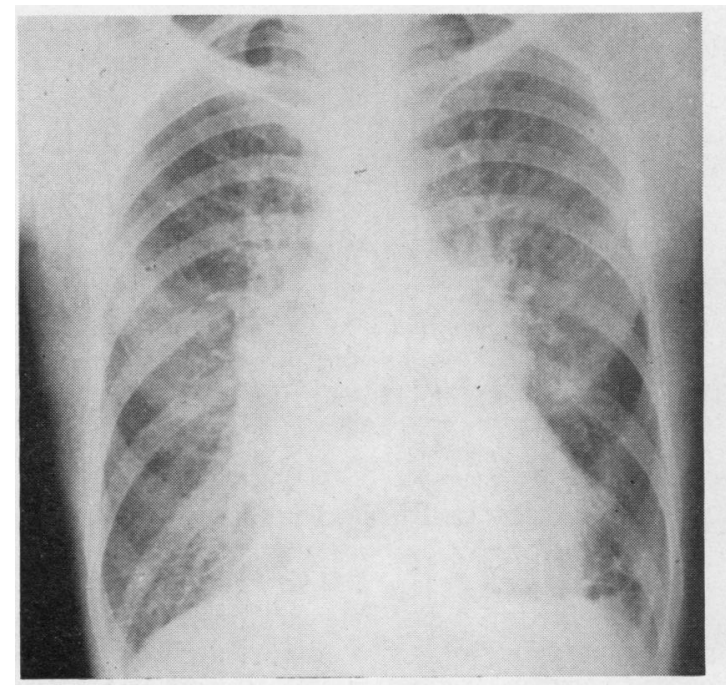

The valve lesion was assessed from clinical, electrocardiographic, radiological, haemodynamic, and angiocardiographic data and from the findings at operation. In most cases there was a combination of mitral stenosis and incompetence, and the patients have been classified in three main groups ; five patients had seriously calcified valves with predominant stenosis, nine had predominant incompetence with some stenosis, and two had uncomplicated mitral incompetence. Slight aortic valve disease was present in six patients.

Satisfactory cardiac catheterization data had been obtained in the few months before operation in 10 patients (Table II). These studies showed a raised mean right atrial pressure $(2 \mathrm{~mm}$. $\mathrm{Hg}$ or more) in six cases. The pulmonary artery pressure averaged $70 / 30 \mathrm{~mm}$. $\mathrm{Hg}$, with a mean of $43 \mathrm{~mm}$. $\mathrm{Hg}$. The pulmonary artery wedge pressure was between 15 and $30 \mathrm{~mm}$. $\mathbf{H g}$, with an average of $24 \mathrm{~mm}$. Hg. The arteriovenous oxygen difference was between 52 and $85 \mathrm{cc}$./l., with an average of $67 \mathrm{cc} . / 1$., and the cardiac index was between 1.4 and $2.61 . / \mathrm{min} . / \mathrm{m}^{2}$, with an average of 2.01 ./ $\mathrm{min} . / \mathrm{m} .^{2}$ The pulmonary vascular resistance was more than 5 units in five cases.

No pre-operative study was performed in the blind patient operated on in pregnancy (A. C.), but enough information was available in the other five patients to allow an assessment of the pulmonary vascular resistance. In $A . L$. and $C . H$. the pre-operative study was performed a year or more before operation; the pulmonary vascular

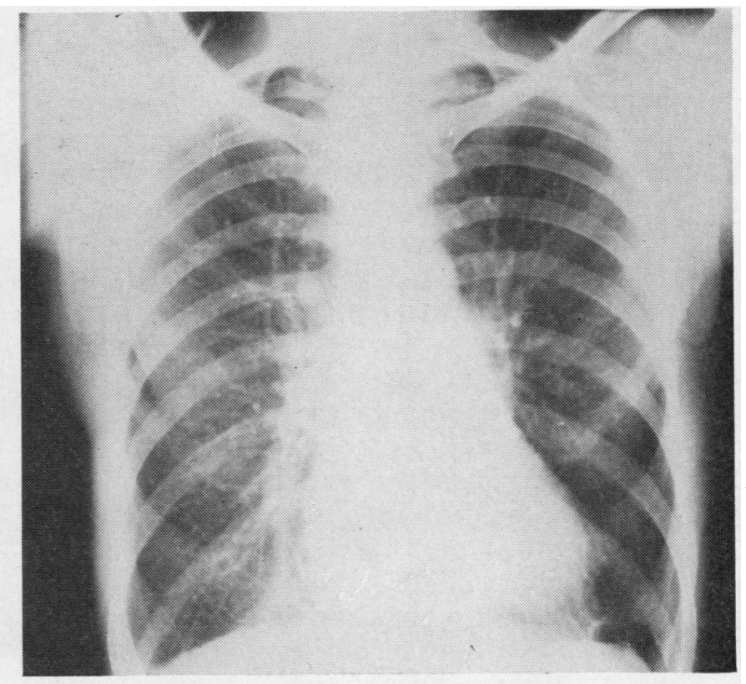

FIG. 2. E.G. Pre-operative (left) and post-operative (right) chest radiographs. Severe pulmonary congestion has resolved after the operation. 
T A B L E I I

FINDINGS AT CARDIAC CATHETERIZATION IN 10 PATIENTS BEFORE AND AFTER MITRAL VALVE REPLACEMENT

\begin{tabular}{|c|c|c|c|c|c|c|c|c|c|c|c|c|c|c|c|c|}
\hline & \multirow{2}{*}{\multicolumn{2}{|c|}{$\begin{array}{l}\text { Time from } \\
\text { Operation } \\
\text { (mths) }\end{array}$}} & \multirow{2}{*}{\multicolumn{2}{|c|}{$\begin{array}{l}\text { R.A.P. } \\
\text { (Mean) }\end{array}$}} & \multicolumn{4}{|c|}{$\begin{array}{l}\text { Pulmonary Artery Pressure } \\
\text { (mm. Hg) }\end{array}$} & \multirow{2}{*}{\multicolumn{2}{|c|}{$\begin{array}{l}\text { P.A. Wedge } \\
\text { Pressure } \\
\text { (mm. Hg) }\end{array}$}} & \multirow{2}{*}{\multicolumn{2}{|c|}{$\begin{array}{l}\text { Arteriovenous } \\
\mathrm{O}_{2} \text { Diff. } \\
\text { (cc. 1.) }\end{array}$}} & \multirow{2}{*}{\multicolumn{2}{|c|}{$\begin{array}{l}\text { Cardiac Index } \\
\left(1 . / \mathrm{min} . / \mathrm{m}^{2}\right)\end{array}$}} & \multirow{2}{*}{\multicolumn{2}{|c|}{$\begin{array}{l}\text { P.V.R. } \\
\text { (units) }\end{array}$}} \\
\hline & & & & & \multicolumn{2}{|c|}{ Before } & \multicolumn{2}{|c|}{ After } & & & & & & & & \\
\hline & Before & After & Before & After & $\begin{array}{l}\text { Sys.! } \\
\text { dias. }\end{array}$ & Mean & $\begin{array}{l}\text { Sys. } \\
\text { dias. }\end{array}$ & Mean & Before & After & Before & After & Before & After & Before & After \\
\hline $\begin{array}{l}\text { L. S. } \\
\text { G. W. } \\
\text { E. C. } \\
\text { J. O. } \\
\text { J. M. } \\
\text { D. B. } \\
\text { H. B. } \\
\text { D. E. } \\
\text { E. G. } \\
\text { G. R. }\end{array}$ & $\begin{array}{l}1 \\
4 \\
1 \\
1 \\
8 \\
1 \\
2 \\
2 \\
4 \\
2\end{array}$ & $\begin{array}{r}18 \\
17 \\
15 \\
10 \\
9 \\
9 \\
8 \\
8 \\
5 \\
3\end{array}$ & $\begin{array}{r}7 \\
2 \\
4 \\
6 \\
-2 \\
-1 \\
3 \\
5 \\
-1 \\
\end{array}$ & $\begin{array}{r}1 \\
-1 \\
1 \\
-1 \\
-1 \\
-1 \\
6 \\
-1 \\
-2 \\
-1\end{array}$ & $\begin{array}{l:l}85 & 30 \\
53 & 20 \\
90 & 35 \\
90 & 45 \\
50 & 20 \\
40 & 15 \\
65 & 20 \\
80 / 30 \\
60 / 30 \\
90 & 50\end{array}$ & $\begin{array}{l}55 \\
30 \\
55 \\
50 \\
32 \\
20 \\
33 \\
50 \\
40 \\
65\end{array}$ & $\begin{array}{l:l}25 & 10 \\
23 & 5 \\
23 & 4 \\
30 & 8 \\
50 & 20 \\
25 & 10 \\
35 & 20 \\
32 & 13 \\
25 & 8 \\
50 & 25\end{array}$ & $\begin{array}{l}15 \\
13 \\
10 \\
16 \\
34 \\
15 \\
28 \\
17 \\
11 \\
30\end{array}$ & $\begin{array}{l}30 \\
25 \\
30 \\
30 \\
20 \\
15 \\
21 \\
18 \\
23 \\
25\end{array}$ & $\begin{array}{r}8 \\
5 \\
1 \\
1 \\
30 \\
8 \\
14 \\
5 \\
2 \\
6\end{array}$ & $\begin{array}{l}85 \\
56 \\
60 \\
72 \\
52 \\
69 \\
67 \\
71 \\
57 \\
84\end{array}$ & $\begin{array}{l}54 \\
53 \\
33 \\
41 \\
46 \\
46 \\
67 \\
52 \\
52 \\
52\end{array}$ & $\begin{array}{l}1.4 \\
1.9 \\
2.2 \\
2.1 \\
2.6 \\
1.8 \\
2.0 \\
1.9 \\
2.6 \\
1.9\end{array}$ & $\begin{array}{l}2 \cdot 6 \\
2 \cdot 4 \\
4 \cdot 0 \\
3 \cdot 2 \\
3 \cdot 3 \\
2 \cdot 7 \\
2 \cdot 0 \\
2 \cdot 7 \\
2 \cdot 8 \\
2 \cdot 4\end{array}$ & $\begin{array}{r}10 \\
2 \\
8 \\
6 \\
2 \\
2 \\
4 \\
11 \\
4 \\
10\end{array}$ & $\begin{array}{l}1 \\
2 \\
1 \\
3 \\
1 \\
2 \\
4 \\
3 \\
2 \\
5\end{array}$ \\
\hline Mean & 3 & 11 & 3 & 0 & $70: 30$ & 43 & 3212 & 19 & 24 & 8 & 67 & 50 & $2 \cdot 0$ & $2 \cdot 8$ & 6 & 2 \\
\hline
\end{tabular}

R.A.P., right atrial pressure $(\mathrm{mm}$. $\mathrm{Hg}$ ). P.V.R., pulmonary vascular resistance.

resistances were 5 and 3 units respectively. In I. S., V. G., and E. A. pressure measurements were obtained, but the cardiac output was not known; the pulmonary vascular resistances were estimated on the basis of cardiac output measurements in similar cases as approximately 3, 5, and 11 units respectively.

COMPLICATIONS AND MORTALITY The mortality of the procedure was not related to the severity of the heart disease or to the type of open heart surgery. One death was due to cerebral damage and three to cardiac damage during the procedure. One other patient had an operative cerebral lesion which left a mild hemiplegia, and another showed left bundle-branch block in the electrocardiogram after the operation.

Repeated ventricular fibrillation was frequent in the immediate post-operative period in early cases and was attributed to the combination of alkalosis and hypokalaemia. The reduction in the stiffness of the lungs as the pulmonary congestion subsides in the first few days after operation may lead to hyperventilation on the respirator and so provoke the arrhythmia. Post-operative oliguria was troublesome in three patients, and serious jaundice developed in four patients who had tricuspid incompetence before the operation. Epileptic fits occurred in two patients. Haemothorax was the final incident in one of the fatal cases. Two patients had post-operative pericarditis. No serious pulmonary complications occurred in these patients. In A. C. the pregnancy was not disturbed, and continued to normal delivery of a live baby.

The heart disease did not seem unusually severe in the four fatal cases (Fig. 3). The degree of breathlessness and of heart failure was similar to that found in the patients who survived the operation, and there was no tendency to more tricuspid incompetence or right ventricular hypertrophy. Cardiac catheterization showed a similar degree of pulmonary vascular obstruction in the two groups.

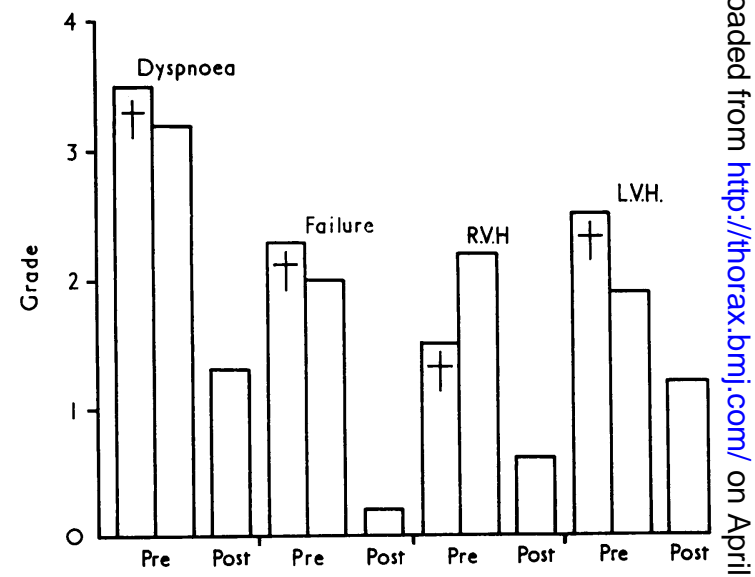

FIG. 3. Average pre- and post-operative clinical findings. N The columns marked with a cross indicate the four patients who died. After operation there is a striking improvement $N$ in dyspnoea, congestive failure, and right ventricular $\mathrm{W}_{\mathrm{J}}$ hypertrophy.

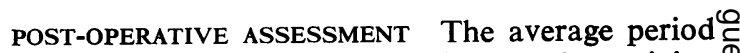
of post-operative observation in the 12 surviving patients is two years. Most patients show a striking improvement in symptoms and in the clinical evidence of heart disease, and many have $\overrightarrow{\mathbb{D}}$ gained weight. Two patients (J. M. and H. B.) with $\frac{?}{\mathrm{Q}}$ relatively little improvement have evidence of $\varrho$ some regurgitation alongside the prosthetic valve: 
one of these subjects has a mild haemolytic anaemia with haemoglobin levels around $70 \%$ and a red cell half-life of 20 days, which is probably secondary to the haemodynamic disturbances. These two patients remain dyspnoeic on exertion and require diuretic therapy. The remaining 10 patients have received considerable benefit from the operation and are now only slightly breathless, although they are not receiving diuretic therapy (Table I). Atrial fibrillation persists in all patients, apart from A. C., who was in normal sinus rhythm before the operation, but none of the patients has more than a slight elevation of venous pressure (Fig. 3). There has been a consistent reduction in the clinical and electrocardiographic evidence of right ventricular hypertrophy (Fig. 4). Left ventricular hypertrophy, on the other hand, became less in some subjects (Fig. 5) but did not change significantly in seven, including one of the patients presumed to have regurgitation alongside the prosthesis.

A review of the radiographs after operation showed a variable effect on the cardiothoracic ratio. In five patients the ratio was reduced by $5 \%$ or more, but the patient with mitral stenosis before operation (A. C.) had a significantly larger heart after the procedure. The remaining patients showed little change in heart size. The pulmonary artery, right atrium (Fig. 6), and left atrium (Fig. 7) often became smaller after the operation, and the radiological evidence of pulmonary congestion was lost in nearly all the patients.

One patient (J. M.) had a cerebral embolus two days after operation but has made a good recovery. All patients have had anticoagulant therapy, beginning a few days after operation, and there has been no other embolic incident.

Satisfactory haemodynamic studies had been performed a few months before operation in 10 of the 12 surviving patients. All the 10 patients readily agreed to a further right heart catheterization to assess their improvement after operation. No post-operative investigation was attempted in the two patients who had not been studied before operation. The post-operative cardiac catheterization studies were performed from three to 18 months after surgery (Table II). The mean systemic venous pressure was normal after operation in nine of the 10 patients. The pulmonary artery pressures fell to an average of $32 / 12 \mathrm{~mm}$. $\mathrm{Hg}$ after operation, with a mean of $19 \mathrm{~mm}$. Hg (Fig. 8). The average value of the mean pulmonary artery wedge pressure fell to $8 \mathrm{~mm}$. $\mathrm{Hg}$ after operation. Apart from the two subjects with unsatisfactory results due to regurgitation along- side the prosthesis, the wedge pressure was $8 \mathrm{~mm}$. $\mathrm{Hg}$ or less, and the average for the eight patients without this complication was $5 \mathrm{~mm}$. Hg (Fig. 9).

The arteriovenous oxygen difference fell after operation to between 41 and $67 \mathrm{cc}$./1., with an average of $50 \mathrm{cc}$./litre. The cardiac index rose to between 2.0 and $4.01 . / \mathrm{min} . / \mathrm{m}^{2}$, with an average of $2.81 . / \mathrm{min} . / \mathrm{m}^{2}$ (Fig. 10). The pulmonary vascular resistance fell to between 1 and 5 units, with an average of 2 units (Fig. 11). The three patients with resistances of 10 or 11 units before operation had an average value of 3 units after operation. The least change (from 10 to 5 units) was found in a patient studied only three months after operation, and the greatest change (from 10 to 1 unit) occurred in a patient studied 18 months post-operatively.

The two patients (J. M. and H. B.) with unsatisfactory results after operation had clinical evidence of persisting mitral regurgitation, presumably due to a leak alongside the prosthesis. Both had elevated wedge pressures $(30$ and $14 \mathrm{~mm}$. $\mathrm{Hg}$ respectively) and pulmonary artery pressures (34 and $28 \mathrm{~mm}$. $\mathrm{Hg}$ respectively). J. M. was anaemic (Hb 9.8 g./100 ml.) and had a relatively high cardiac output $\left(3.3 \mathrm{l} . / \mathrm{min} . / \mathrm{m}^{2}\right)$ and a raised systemic venous pressure. H. B. was not anaemic but had a low cardiac index $\left(2.01 . / \mathrm{min} . / \mathrm{m}^{2}\right)$ and a low arterial oxygen saturation (84\%). The haemoglobin values and arterial oxygen saturations were normal in the other patients. One patient (G. W.) had mild systemic hypertension after operation (B.P. $180 / 100 \mathrm{~mm}$. $\mathrm{Hg}$ ), but in the other subjects the arterial pressure was normal.

\section{DISCUSSION}

The clinical and haemodynamic changes found in these patients are an indication of the improvement that may follow mechanical correction of the valve abnormality in patients with severe rheumatic heart disease. The increased well-being of the patients is striking but is difficult to measure objectively. A considerable gain in weight in spite of the loss of oedema suggests that the patients are recovering from cardiac cachexia. The absence of serious symptoms after operation is, of course, to some extent a reflection of the gross limitation of activities pre-operatively, and, although dyspnoea is not troublesome in the course of the patients' usual daily activities, it is difficult to be sure of the degree of limitation. Nevertheless, these patients are able to lead normal lives and to return to sedentary occupations. 
G.R.

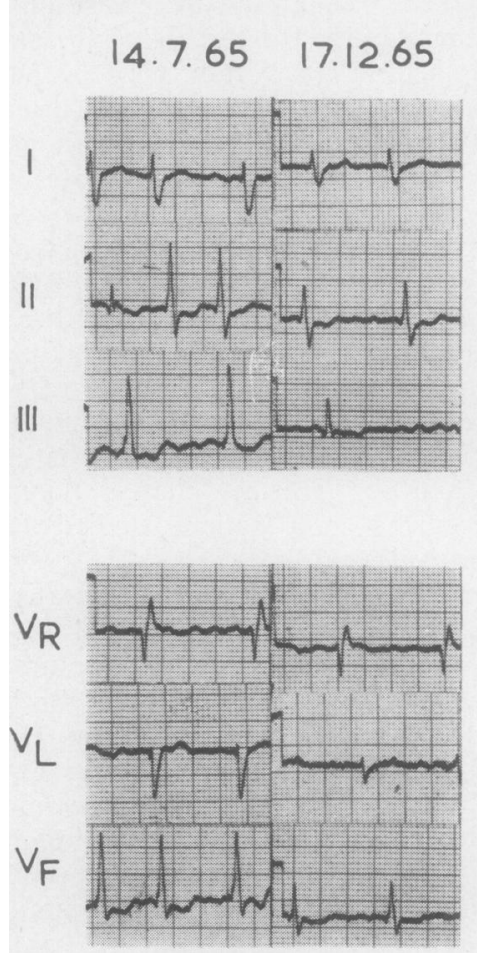

FIG. 5. L.S. Pre-operative (23.4.64) and post-operative (30.11.65) electrocardiograms. There is some reduction in the severity of left ventricular hypertrophy after operation.
14.7 .65
17.12 .65
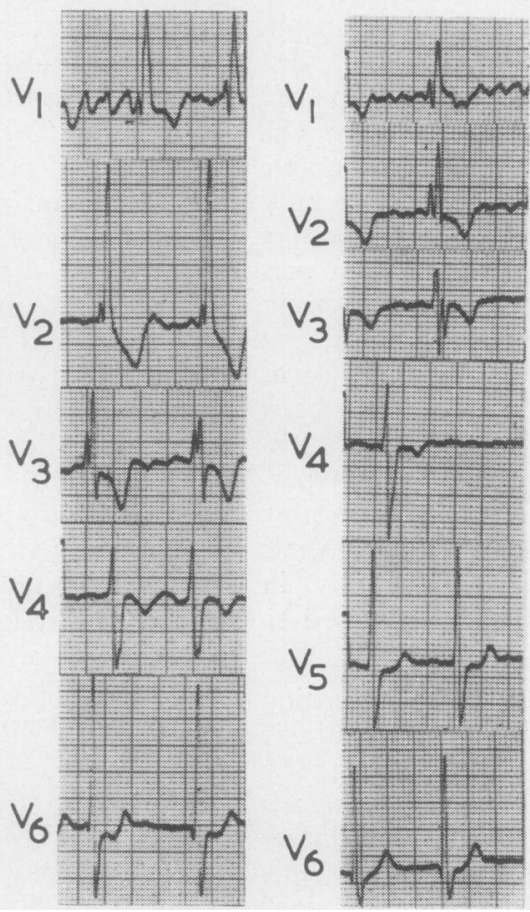

L.S

\section{$23.4 .64 \quad 30.11 .65$}

23. 4.6430 .11 .65

II
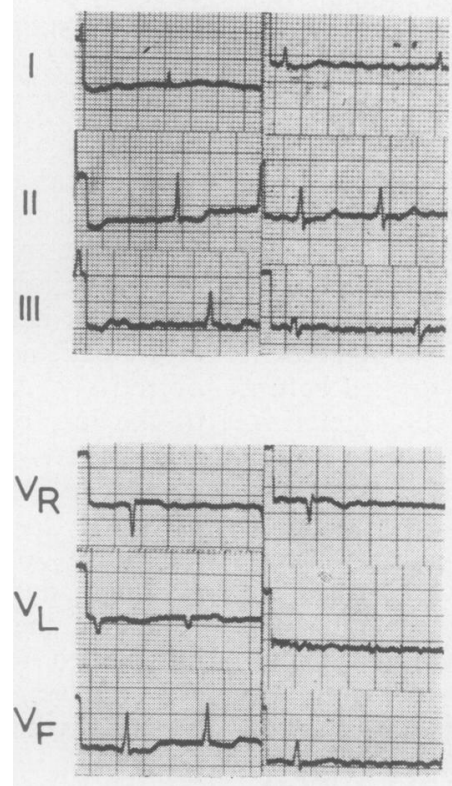

FIG. 4. G.R. Pre-operative (14.7.65) and post-operative (17.12.65) electrocardiograms. There is considerable reduction in the severity of the right ventricular hypertrophy after operation. 

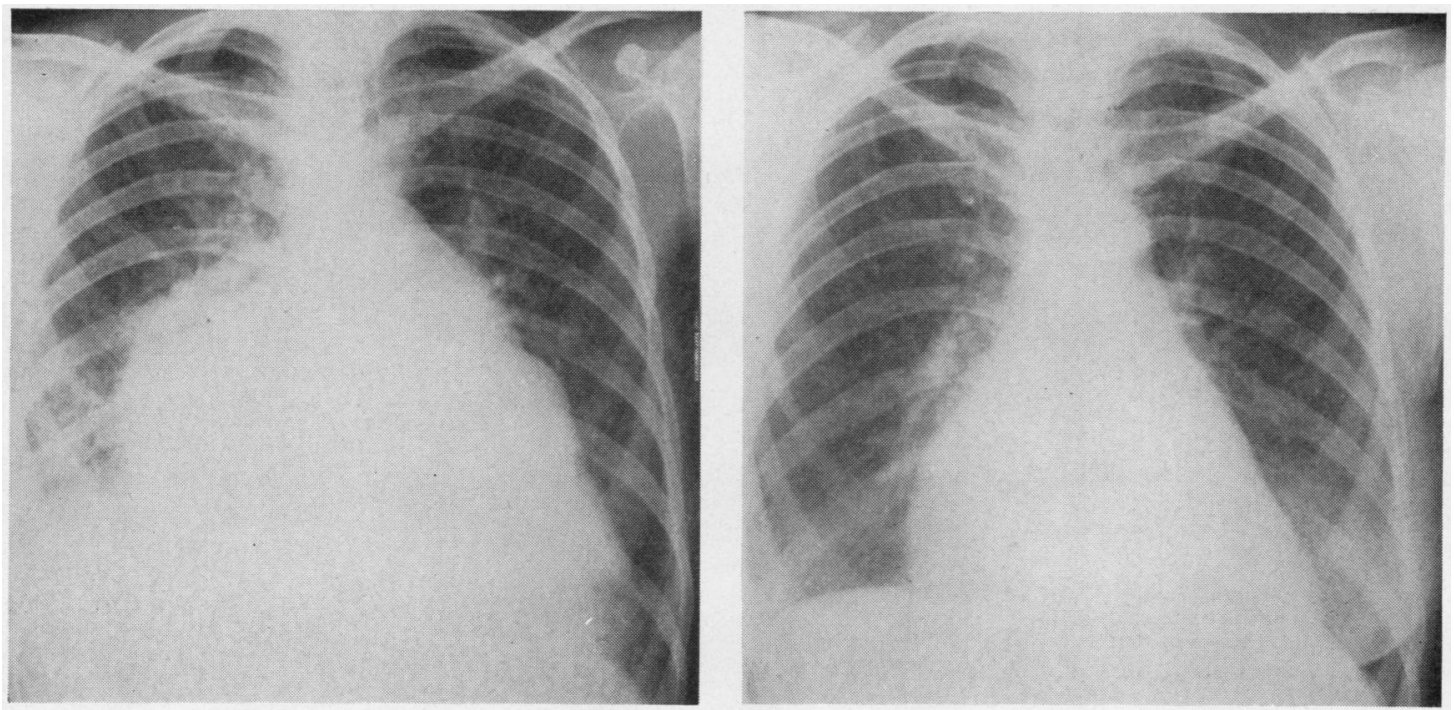

FIG. 6. E.C. Pre-operative (left) and post-operative (right) chest radiographs. There is considerable reduction in the size of the pulmonary artery and right atrium after operation.

Although there is considerable improvement after operation, the persistent ventricular hypertrophy and enlargement of the heart in the chest radiograph are evidence of myocardial disturbances which may be irreversible. Rastelli, Kincaid, and Kirklin (1966) report similar findings in the chest radiograph after mitral valve replacement and suggest that impaired left ventricular perfor-

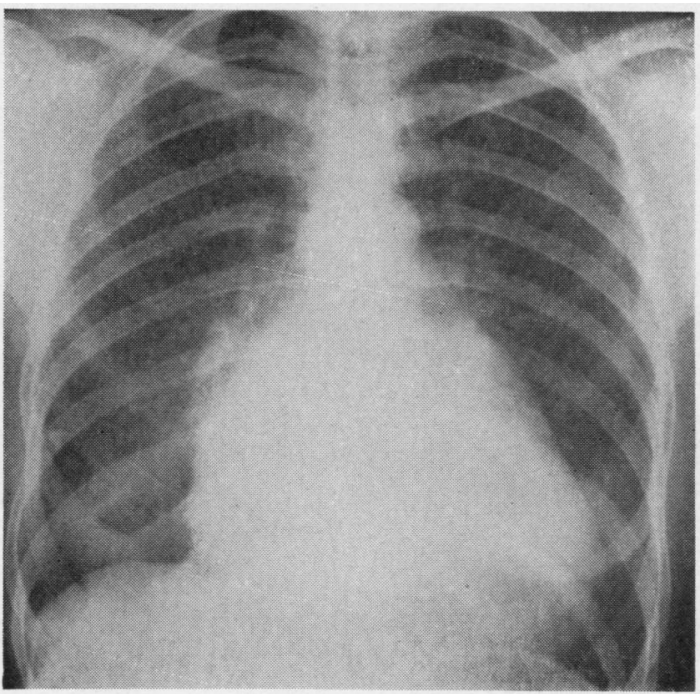

mance is responsible for the large heart after the operation. Hubis and Hultgren (1965) have also demonstrated considerable disturbances in myocardial function after mitral valve replacement, and the long-term outlook for these patients is problematical.

The cardiac catheterization findings after operation indicate mild obstruction to flow at the

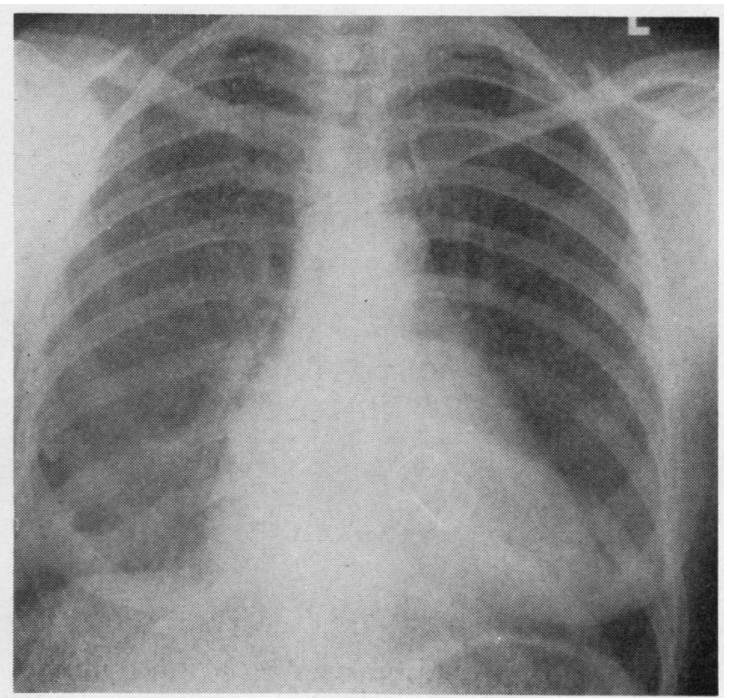

FIG. 7. D.E. Pre-operative (left) and post-operative (right) chest radiographs. The left atrium is reduced in size after the operation. The over-penetrating post-operative film shows the prosthesis clearly. 


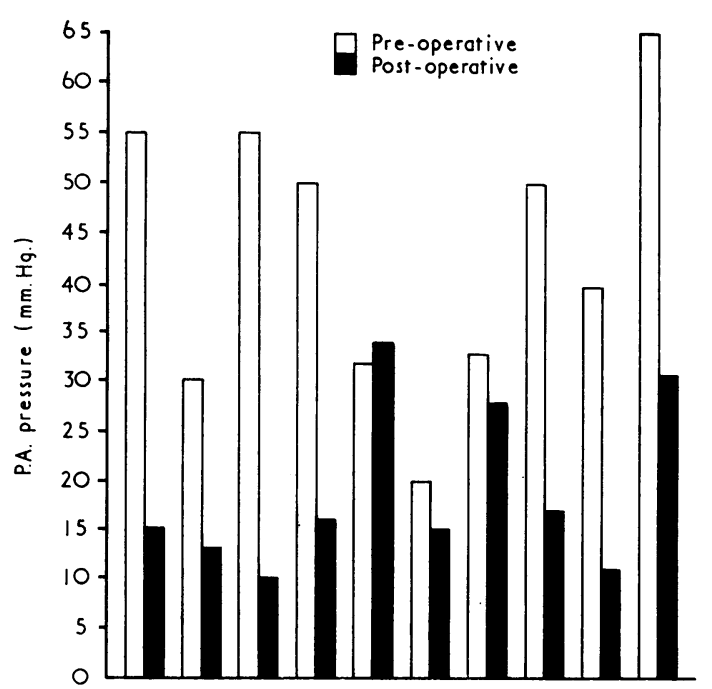

FIG. 8. Pulmonary artery mean pressures before and after operation. There is a consistent fall in pressure after operation, except in two patients with regurgitation alongside the prosthesis.

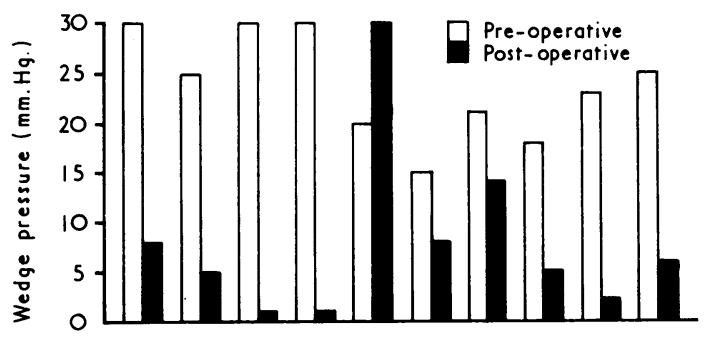

FIG. 9. Pulmonary artery wedge mean pressures before and after operation. The post-operative pressure is near to the normal range, except in two patients with regurgitation alongside the prosthesis.

mitral valve prosthesis, as expected from the size of the orifice of the artificial valve. Four of the eight patients without post-operative complications had wedge pressures slightly above $5 \mathrm{~mm}$. $\mathrm{Hg}$. These values are similar to the left atrial pressures reported by Morrow, Clark, Harrison, and Braunwald (1964), who found an average gradient across the prosthesis of $5 \mathrm{~mm}$. $\mathrm{Hg}$ at rest. It is clear that there can be no significant elevation of left ventricular diastolic pressure in these patients.

The importance of pulmonary vascular obstruction in mitral valve disease, and the consequent development of right ventricular failure, has been described by Wood (1954). The pulmonary vascular resistance, calculated as the ratio between the pressure gradient from pulmonary arteries to pulmonary veins and the pulmonary blood flow, $\stackrel{\overrightarrow{5}}{\stackrel{\vec{S}}{+}}$ is a useful indication of the severity of these changes in the pulmonary vessels. However, measurements of the pulmonary vascular resis- $\frac{\bar{m}}{7}$ tance may be increased by cardiac factors which $\stackrel{\Phi}{\varnothing}$ reduce pulmonary blood flow and so diminish the distension of the pulmonary vascular bed. A higher resistance does not therefore necessarily indicate more severe disease of the pulmonary vessels.

The considerable improvement in tricuspid $\vec{x}$ incompetence and in right ventricular hypertrophy, and the reduction in the size of the pulmonary artery in the radiograph, suggested that $\overrightarrow{\overrightarrow{.}}$ the pulmonary vascular obstruction in our patients $\mathrm{O}$ had become less severe after operation, and the

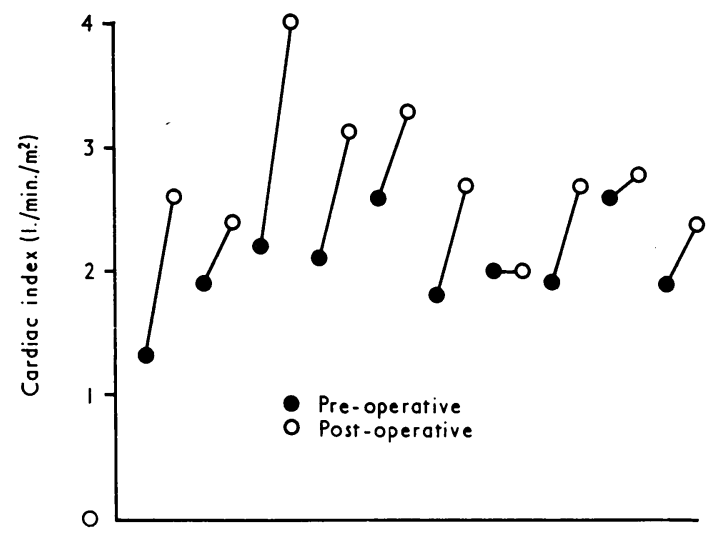

FIG. 10. Cardiac output, expressed in terms of body surface area, before and after operation.

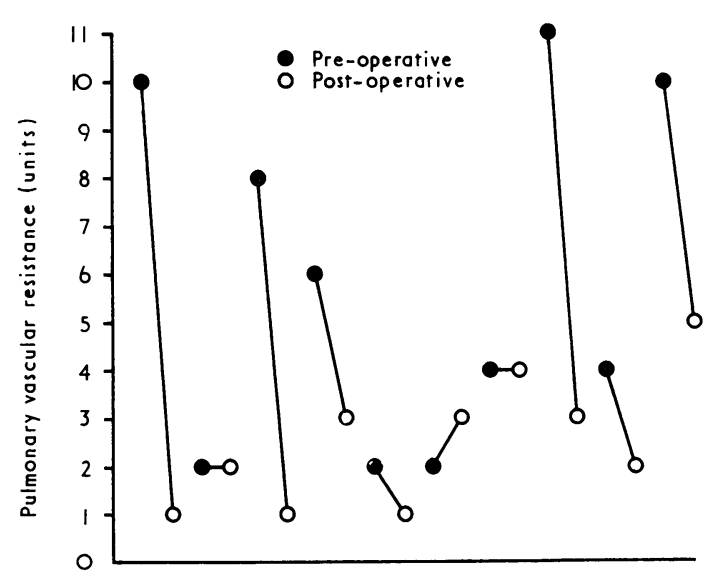

FIG. 11. Pulmonary vascular resistance before and after mitral valve replacement. 
findings at cardiac catheterization tend to confirm this view. The reduction in pulmonary artery pressure after operation is greater than would be expected from the fall in left atrial pressure, particularly in view of the increase in cardiac output. The increase in cardiac output may be secondary to the resolution of pulmonary vascular obstruction, but the change in output is not confined to the high resistance cases. An alternative view is that the improvement in cardiac output results from correction of the abnormalities of the mitral valve and produces some dilatation of the resistance vessels in the lungs. However, the fall in pulmonary vascular pressures will produce a tendency for the resistance vessels to close, which will oppose the dilating effect of an increase in cardiac output. In these circumstances the reduction in the pressure gradient between the pulmonary arteries and the pulmonary veins in our patients is good evidence of resolution of the pulmonary vascular obstruction after operation. The findings are similar to those reported after mitral valve replacement by Braunwald, Braunwald, Ross, and Morrow (1965). They describe 31 patients with pulmonary artery systolic pressures above $50 \mathrm{~mm}$. $\mathrm{Hg}$ before operation. The mean value for the resistance fell from 8 to 3 units after operation while the output rose from 2.0 to 3.0 $1 . / \mathrm{min} . / \mathrm{m}^{2}$

The effect of mitral valvotomy on the pulmonary vascular resistance has been difficult to assess. In some cases the results of valvotomy are not fully satisfactory because of inadequate relief of the stenosis or the development of mitral incompetence, and these disturbances may lead to persistence of a high left atrial pressure and a low cardiac output. In these circumstances the pulmonary vascular resistance may be little changed by operation. Emanuel (1963) reported persistent elevation of pulmonary vascular resistance in spite of an apparently adequate valvotomy in two subjects, and suggests that the pulmonary vascular disease may be irreversible in these patients. However, assessment of the results of valvotomy is difficult, as a rigid calcified valve may offer considerable obstruction in spite of division of the commissures. The consistent reduction in pulmonary vascular resistance after mitral valve replacement suggests that the failure of the resistance to fall after other operations is due to inadequate correction of the mitral valve abnormalities. Clearly the residual obstruction produced by the mitral valve prosthesis does not prevent a reduction in the pulmonary vascular resistance, even though considerable elevation of left atrial pressure may occur on exercise (Morrow et al.,
1964). This finding is consistent with the absence of serious pulmonary hypertension in mild mitral stenosis.

The resolution of the high pulmonary vascular resistance in our patients is not inconsistent with the presence of structural changes in the pulmonary vascular bed. It does suggest that the increase in resistance is a secondary effect of elevation of pulmonary venous pressure and the consequent interstitial pulmonary oedema. A rapid initial improvement, due to the reduction in left atrial pressure and increase in cardiac output, and also the loss of any vasoconstrictive pulmonary vascular obstruction, is probably important in the immediate post-operative phase. The persistence of some increase in resistance in the patient studied three months after operation suggests that gradual improvement in the structural pulmonary vascular changes may continue for several months. Although resistance values near the normal have been found after operation in our patients, it would be unwise to expect complete resolution of the organic changes in the pulmonary vascular bed.

We have not operated on the tricuspid valve in any of these patients and there has been a striking reduction in the degree of tricuspid incompetence after operation. We have found, as have Braunwald, Ross, and Morrow (1966), that tricuspid incompetence secondary to dilatation of the right ventricle will resolve as the pulmonary artery pressure falls, and we do not consider that tricuspid valve replacement is required in these circumstances.

A high pulmonary vascular resistance is often regarded as a contraindication to open heart surgery because of the high mortality rate. In the present series there was no undue mortality in patients with an increased pulmonary vascular resistance. We attribute this largely to efficient mechanical ventilation with a high concentration of oxygen in the immediate post-operative period. Although six of our 16 patients had pulmonary vascular resistances over 5 units, none had values in the extremely high range. Our subsequent experience in patients with very high resistances has been less satisfactory than in the patients reported here, and three of our four patients with resistances over 14 units have died (Table III). The very high pulmonary vascular resistance in these patients may be in part an indication of a very low cardiac output rather than of extreme changes in the pulmonary vessels, and it is our view that with further experience the mortality rate can be reduced in this group. Certainly the relatively low mortality in the less severely affected patients, 
T A B L. E I I I

MORTALITY OF MITRAL VALVE REPLACEMENT: FIRST 50 PATIENTS

\begin{tabular}{c|c|c|c}
\hline $\begin{array}{c}\text { Pulm. Vascular } \\
\text { Resistance (units) }\end{array}$ & No. & Deaths & $\begin{array}{c}\text { Mortality } \\
(\%)\end{array}$ \\
\hline $0-4$ & 19 & 4 & 21 \\
$5-9$ & 17 & 2 & 12 \\
$10-14$ & 10 & 2 & 20 \\
$>14$ & 4 & 3 & 75 \\
\hline Total & 50 & 11 & 22 \\
\hline
\end{tabular}

and the great possible benefit of the operation, make it clear that a high pulmonary vascular resistance should not be regarded as a bar to mitral valve replacement.

Our thanks are due to the nursing staff of the Thoracic Surgical Unit, St. Bartholomew's Hospital, whose efficiency and dedication have contributed very greatly to the success of the operations reported here.

\section{BIBLIOGRAPHY}

Braunwald, E., Braunwald, N. S., Ross, J., and Morrow, A. G. (1965) Effects of mitral valve replacement on the pulmonary vascular dynamics of patients with pulmonary hypertension. Circulaticn, ڤొ
32, Supplement II, 58.

Braunwald, N. S., Ross, J., and Morrow, A. G. (1966). The conservative management of tricuspid regurgitation in patients undergoing mitral valve replacement. Abst. Vth Wld Congr. Cardiol., 11, 29.

Emanuel, R. (1963). Valvotomy in mitral stenosis with extreme pulmonary vascular resistance. Brit. Heart J., 25, 119.

Hubis, H. J., and Hultgren, H. N. (1965). Cardiac dysfunction following prosthetic replacement of the mitral valve. Circulation, 32 Supplement II, 116.

Morrow, A. G., Clark, W. D., Harrison, D. C., and Braunwald, E. (1964). Prosthetic replacement of the mitral valve: Operative methods and the results of preoperative and postoperative hemodynamic assessments. Ibid., 29, Supplement 1, 2.

Rastelli, G. C., Kincaid, O. W., and Kirklin, J. W. (1966). Heart size after isolated replacement of mitral or aortic valve. Mayo Clin. Proc., 41, 217.

Starr, A., and Edwards, M. L. (1961). Mitral replacement: clinical experience with a ball-valve prosthesis. Ann. Surg., 154, 726.

Wood, P. (1954). An appreciation of mitral stenosis. Part 1. Clinical features. Brit. med. J., 1, 1051. 